\title{
KAJIAN KUALITAS TANAH PADA BUDIDAYA PADI INTENSIF DENGAN PENGELOLAAN PENGAIRAN DAN PEMUPUKAN
}

\author{
${ }^{1}$ Ebsan Marihot Sianipar ${ }^{\otimes},{ }^{2}$ Khadijah Ramijah \\ ${ }^{1}$ Universitas Methodist Indonesia, Medan, Indonesia \\ ${ }^{2}$ Balai Pengkajian Teknologi Pertanian (BPTP) Sumatera Utara, Indonesia \\ Email: sianiparebsan@gmail.com
}

DOI: https://doi.org/10.46880/methoda.Vol11No3.pp217-223

\begin{abstract}
Intensive and efficient rice cultivation based on irrigation and fertilization management is something that the government is currently pursuing. The purpose of the study was to analyze changes in soil quality in intensive rice cultivation on technically irrigated rice fields. The study was arranged using a split plot randomized block design (Split Plot), with the treatment of the irrigation system as the main plot factor, namely the intermittent irrigation system and the continuous flow system (inundation); Fertilization as a sub-plot factor, namely fertilization treatment was carried out based on the recommendation of the Minister of Agriculture No. 40 of 2007 and fertilization recommendations based on laboratory analysis with 8 levels of fertilization treatment with 3 replications. The results showed that intensive rice cultivation did not reduce soil quality if an intermittent irrigation system was applied and fertilizer was applied according to the recommendations of laboratory analysis results with a dose of $100 \%$ plus probiotics.
\end{abstract}

Keyword: Intensive, Irrigation, Fertilization, Soil Quality.

\begin{abstract}
ABSTRAK
Budidaya tanaman padi yang intensif dan efisien dengan berbasis pada pengelolaan pengairan dan pemupukan merupakan hal yang sedang diupayakan pemerintah. Tujuan penelitian adalah menganalisis perubahan kualitas tanah pada budidaya padi intensif pada lahan sawah irigasi teknis. Penelitian disusun menggunakan rancangan acak kelompok petak terbagi (Split Plot), dengan perlakuan Sistem Pengairan sebagai faktor petak utama yakni sistem pengairan terputus (intermittent) dan sistem mengalir secara terus menerus (penggenangan); Pemupukan sebagai faktor anak petak yaitu perlakuan pemupukan dilakukan berdasarkan Rekomendasi Permentan No 40 Tahun 2007 dan rekomendasi pemupukan berdasarkan analisis laboratorium dengan 8 taraf perlakuan pemupukan dengan 3 ulangan. Hasil penelitian menunjukkan budidaya pertanaman padi intensif tidak menurunkan kualitas tanah, apabila diterapkannya sistem pengairan intermittent dan pemberian pupuk sesuai dengan rekomendasi hasil analisis laboratorium dengan dosis $100 \%$ ditambah probiotik.
\end{abstract}

Kata Kunci: Intensif, Pengairan, Pemupukan, Kualitas Tanah.

\section{PENDAHULUAN}

Upaya mempertahankan ketahanan pangan nasional dilaksanakan secara simultan melalui pengendalian konversi lahan pertanian; mencetak lahan pertanian baru; dan intensifikasi sistem pertanian dengan menerapkan teknologi yang dapat meningkatkan produktivitas (peningkatan intensitas tanam) dan sekaligus mempertahankan kualitas lingkungan. Peningkatan produktivitas dapat mengalami berbagai kendala diantaranya adalah degradasi dan konversi lahan pertanian (Agus \& Mulyani, 
2006). Indeks Pertanaman Padi 400 (IP Padi 400) yang diprogramkan oleh Departemen Pertanian yang dipelopori oleh Badan Litbang Pertanian dengan tujuan untuk ketahanan pangan dan surplus produksi tahun 2008 sebesar 2.89 juta ton beras. Peluang ekspor dapat dicapai pada tahun 2009-2020 sebesar 0.09-3.19 juta ton beras menjadi harapan ketahanan pangan kini dan masa depan (Departemen Pertanian, 2008).

IP Padi 400 artinya petani dapat menanam dan memanen padi sebanyak empat kali secara rotasi dalam satu tahun, secara terus menerus pada hamparan lahan yang sama dengan konsekuensi penerapan penggunaan bibit padi berumur genjah dan variatif (komposisi penggunaan bibit unggul padi berumur genjah). Jadi Indeks Pertanaman padi menuju 400 atau IP Padi 400 tidak hanya merupakan jumlah frekuensi pertanaman padi dalam satu hamparan atau lahan dalam satu tahun namun merupakan salah satu terobosan baru dengan memadukan seluruh komponen teknologi sehingga peningkatan intensitas tanam dapat dilaksanakan. Untuk mengoptimalisasi produksi padi diperlukan input pupuk anorganik secara komulatif tinggi sesuai kebutuhan tanaman (Zaini, 2012).

Disisi lain, penggunaan pupuk anorganik secara terus menerus menyebabkan penurunan kualitas tanah. Pada sistem pertanian intensif tanaman padi, pemberian pupuk sebagai penambah unsur hara yang ada dalam tanah merupakan keharusan agar tanaman dapat mencukupi kebutuhannya (Yetro, 2014). Peningkatan Indek Pertanaman (IP) merupakan langkah yang lebih operasional dan lebih realistis dalam meningkatkan luas tanam dan panen menuju produksi padi berkelanjutan, karena relatif tidak memerlukan biaya yang besar namun dapat meningkatkan pendapatan petani walaupun dengan berbagai permasalahan yang berkaitan dengan perubahan kualitas lingkungan termasuk kualitas tanah. Tujuan penelitian adalah menganalisis perubahan kualitas tanah pada budidaya padi intensif pada lahan sawah irigasi teknis (Ramija, Manurung, Batubara, \& Susanto, 2016)

\section{METODE PENELITIAN}

Lokasi penelitian untuk budidaya padi intensif dilaksanakan di Desa Nagori/Desa Purbaganda, Kecamatan Pematang Bandar, Kabupaten Simalungun. Lokasi penelitian ini dipilih karena merupakan sawah irigasi teknis yang mempunyai persediaan air selama 11- 12 bulan per tahun sebagai syarat utama penerapan Indeks pertanaman Padi 400. Analisis contoh tanah dan kualitas air dilakukan di Laboratorium Tanah Balai Pengkajian Teknologi Pertanian (BPTP) Sumatera Utara dan Laboratorium Balai Lingkungan Hidup (BLH) Propinsi Sumatera Utara.

Rancangan percobaan yang digunakan adalah rancangan petak terbagi (Split Plot) yang disusun secara kelompok, pengelompokan ini didasarkan pada sulitnya memperoleh keseragaman lingkungan yang ideal di lapangan. Perlakuan Sistem Pengairan sebagai faktor petak utama (A) terdiri dari: $\mathrm{A}_{1}=$ Mengalir; $\mathrm{A}_{2}=$ Intermittent (pengairan berselang/terputus) dan Pemupukan sebagai faktor anak petak atau (B) terdiri dari: $\mathrm{B}_{1}=$ Pemupukan sesuai rekomendasi Permentan No 40/Permentan/OT.140/ 2007; B $=$ Pemupukan sesuai dengan Analisis Laboratorium; $\mathrm{B}_{3}=$ Pemupukan sesuai dengan Permentan No 40 (100\% dosis) + probiotik; $\mathrm{B}_{4}$ $=$ Pemupukan sesuai Permentan No $40 \quad(70 \%$ dosis) + probiotik; $\mathrm{B}_{5}=$ Pemupukan sesuai Permentan No 40 (40\% dosis) + probiotik; $\mathrm{B}_{6}$ $=$ Pemupukan sesuai analisis Laboratorium $(100 \%$ dosis $)+$ probiotik; $\mathrm{B}_{7}=$ Pemupukan sesuai analisis Laboratorium $(70 \%$ dosis $)+$ probiotik; $\mathrm{B}_{8}=$ Pemupukan sesuai dengan analisis Laboratorium ( $40 \%$ dosis) + probiotik. Perlakuan dilakukan dengan 3 kali ulangan, sehingga diperoleh 48 plot percobaan. Pengamatan perubahan sifat-sifat kimia tanah dari cuplikan komposit tanah dilakukan selama empat musim tanam atau lima kali pengambilan contoh tanah. Pengambilan contoh tanah dilakukan sebanyak 5 kali, yaitu :1) setelah olah tanah sebelum tanam MT 1;2) setelah panen MT 1 dan sebelum tanam MT 2;3) setelah panen MT 2 dan sebelum tanam MT 3; 4) setelah panen MT 3 dan sebelum tanam MT 4 dan 5) setelah panen MT 4. 


\section{HASIL DAN PEMBAHASAN}

Hasil analisa tekstur tanah diperoleh bahwa tanah yang digunakan dalam penelitian bertekstur lempung liat berpasir dengan reaksi tanah masam. Menurut kriteria Pusat Penelitian Tanah (1998), kandungan C-organik rendah, Ntotal tergolong rendah, $\mathrm{P}$ tersedia tergolong sedang. Basa-basa dapat ditukar yaitu $\mathrm{K}$ dapat ditukar tergolong rendah, dan $\mathrm{Mg}$ dapat ditukar tergolong tinggi. Kapasitas tukar kation tergolong rendah. Unsur hara mikro $\mathrm{Cu}$ tidak terdeteksi, Mn tergolong sedang dan Fe, B dan S tergolong tinggi, hal ini ditunjukkan pada tabel 1 berikut:

Tabel 1. Sifat Kimia Tanah Awal di Desa Purbaganda, Kecamatan Pematang Bandar, Kabupaten Simalungun

\begin{tabular}{|c|l|c|l|l|}
\hline No. & Jenis Analisis & Nilai & Kriteria & \multicolumn{1}{c|}{ Metode } \\
\hline 1 & $\mathrm{pH}$ & 4,8 & Asam & Elektrometry \\
\hline 2 & C-Organik & 1,38 & Rendah & Spectrophotometry \\
\hline 3 & N-Total & 0,12 & Rendah & Kjeldahl \\
\hline 4 & P-Bray & 10,01 & Sedang & Spectrophotometry \\
\hline 5 & K-dd & 0,25 & Rendah & AAS \\
\hline 6 & $\mathrm{Mg}$ & 0,84 & Tinggi & AAS \\
\hline 7 & $\mathrm{Na}$ & 0,26 & Rendah & AAS \\
\hline 8 & $\mathrm{KTK}$ & 5,77 & Rendah & AAS \\
\hline 9 & $\mathrm{Fe}$ & 1520 & Tinggi & AAS \\
\hline 10 & $\mathrm{~B}$ & 10,78 & Tinggi & Spectrophotometry \\
\hline 11 & $\mathrm{~S}$ & 102,44 & Tinggi & Spectrophotometry \\
\hline 12 & $\mathrm{P} \mathrm{O}_{5}$ & 33,98 & Sedang & Spectrophotometry \\
\hline 13 & $\mathrm{~K} 2 \mathrm{O}$ & 42,33 & Tinggi & AAS \\
\hline \multirow{2}{*}{14} & Tekstur & \multicolumn{3}{|l}{} \\
\cline { 2 - 5 } & Pasir $(\%)$ & 58,2 & & Hydrometer \\
\cline { 2 - 5 } & Debu $(\%)$ & 8,36 & & Hydrometer \\
\cline { 2 - 5 } & Liat $(\%)$ & 33,44 & & Hydrometer \\
\hline
\end{tabular}

Berdasarkan hasil analisa tanah awal pada Tabel 1. terlihat bahwa kesuburan tanah pada lahan penelitian berada pada status rendah. Hal ini karena adanya faktor penghambat utama yakni KTK, kandungan C-organik, N-total dan $\mathrm{K}$-dd yang rendah. Hal ini sejalan dengan pendapat Hardjowigeno (1987), yang mengatakan bahwa tanah-tanah yang telah berkembang lanjut umumnya memiliki nilai KTK yang rendah.

\section{Kualitas Tanah}

Dalam upaya untuk mempelajari sampai sejauh mana adanya perubahan kualitas tanah yang ditunjukkan selama empat musim tanam, maka dilakukan pengamatan perubahan sifat kimia tanah. Indikator penilaian kualitas tanah untuk sifat kimia tanah mencakup $\mathrm{pH}$, kandungan C-organik, N-total, P-tersedia dan K-dapat ditukar (Mitchell, Gaskell, Smith, Fouche, \& Koike, 2000).

\section{pH}

Secara umum rata-rata $\mathrm{pH}$ setiap musim menunjukkan bahwa $\mathrm{pH}$ tanah dengan intermittent lebih tinggi dibandingkan dengan tanah tergenang. Rata-rata $\mathrm{pH}$ tanah dengan intermitten berkisar 4,83 - 5,75 sedangkan perlakuan penggenangan berkisar 4,33 - 4.90. Perlakuan A2B6 (pemupukan analisis lab $(100 \%)+$ probiotik dengan penggenangan intermittent) menunjukkan $\mathrm{pH}$ rata-rata tertinggi adalah 5,49 sedangkan $\mathrm{pH}$ rata-rata terendah adalah 4,57 pada perlakuan A1B7 (pemupukan analisis lab $(70 \%$ dosis $)+$ probiotik dengan penggenangan terus menerus). Hal ini 
kemungkinan disebabkan oleh karena pemupukan yang intensif, terutama pemupukan $\mathrm{N}$ dengan menggunakan urea. Menurut Setyanto, 2004, pemberian Urea $\left(\mathrm{CO}\left(\mathrm{NH}_{2}\right)_{2}\right.$ akan menghasilkan Amonium $\left(\mathrm{NH}_{4}{ }^{+}\right)$yang diserap oleh tanaman padi akan diseimbangkan dengan pelepasan $\mathrm{H}^{+}$, sehingga menyebabkan $\mathrm{pH}$ menurun.

Pada Gambar 1. dapat dilihat bahwa $\mathrm{pH}$ tanah berfluktuasi sesuai dengan perlakuan. Pada MT I rata-rata $\mathrm{pH} 4,86$ kemudian meningkat menjadi pH 5,05 pada MT II, pada MT III pH 5,06 dan pada MT IV pH 4,86. Hal ini menunjukkan bahwa $\mathrm{pH}$ tanah secara umum relatif stabil dengan intensitas empat musim tanam setahun. Perlakuan A1B1, A1B2, A1B4, A1B5, A1B6, A1B7, A1B8, A2B1, A2B2, A2B7 dan A2B8 memperlihatkan kecenderungan $\mathrm{pH}$ meningkat selama empat musim tanam. Perlakuan yang mengalami peningkatan $\mathrm{pH}$ secara umum terjadi pada perlakuan Al yakni perlakuan penggenangan terus-menerus. Kenaikan $\mathrm{pH}$ tanah untuk perlakuan tergenang (A1B1, A1B2, A1B4, A1B5, A1B6, A1B7, dan A1B8) disebabkan oleh beberapa faktor, seperti perubahan besi feri menjadi fero, sulfat menjadi sulfida, dan $\mathrm{CO}_{2}$ menjadi $\mathrm{CH}_{4}$ (Ismunadji, Partohardjono, Syam, \& Widjono, 1988). Pada umumnya $\mathrm{pH}$ tanah sawah yang digenangi akan meningkat mendekati netral, hal ini disebabkan oleh adanya reaksi reduksi yang menghasilkan proton (Hartatik, Widowati, Retno, \& Sulaeman, 2007). Aluminium dari mineral liat yang digantikan oleh kation lain, akan terhidrolisis menjadi senyawa kompleks aluminium hidroksida yang berupa endapan yang tidak meracuni tanaman. Hidrolisis $\mathrm{Al}^{3+}$ menghasilkan $\mathrm{H}^{+}$yang menurunkan $\mathrm{pH}$. Namun pada tanahtanah dengan $\mathrm{pH}<4$ tidak memberikan kenaikan $\mathrm{pH}$ pada penggenangan. Hal ini diduga karena tidak aktifnya mikroba yang mengkatalisasi reaksi reduksi. Hal ini pula yang menyebabkan nilai $\mathrm{pH}$ pada perlakuan penggenangan tidak meningkat karena $\mathrm{pH}$ awal tergolong rendah yaitu 4,8 sedangkan nilai $\mathrm{pH}$ tanah pada perlakuan intermittent lebih tinggi walaupun masih dalam kriteria rendah (masam), disebabkan proses oksidasi dan reduksi yang terjadi secara bergantian (Hartatik et al., 2007).

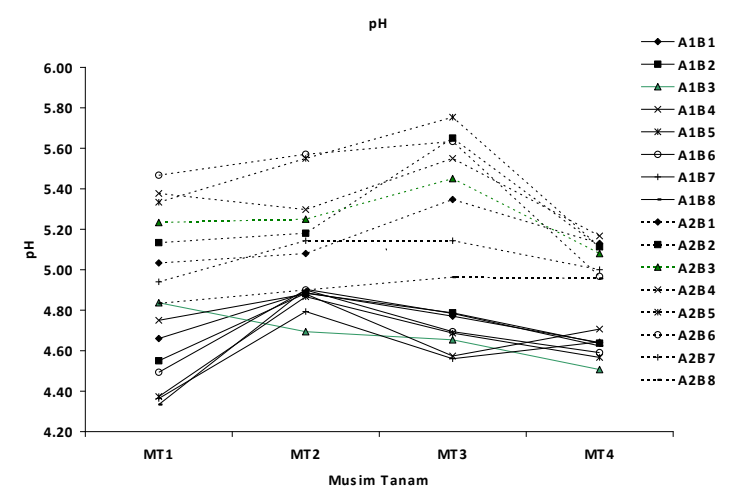

Gambar 1. Grafik pH Tanah selama Empat Musim Tanam

\section{C-Organik}

Kandungan C-organik tanah dapat menggambarkan kesuburan tanah. Penilaian kadar C-organik awal tergolong kriteria rendah dan semakin menurun pada MT I, MT II, MT III, dan MT IV yaitu dari kadar C-organik 1,38 pada analisis tanah awal dan menjadi 1,19 pada MT IV. Kondisi ini menunjukkan bahwa kegiatan budidaya padi secara intensif selama empat musim tanam dalam setahun dapat mengakibatkan menurunnya kandungan corganik tanah. Untuk hal ini maka perlu diperhatikan pengelolaan bahan organik pada lahan penanaman padi secara intensif.

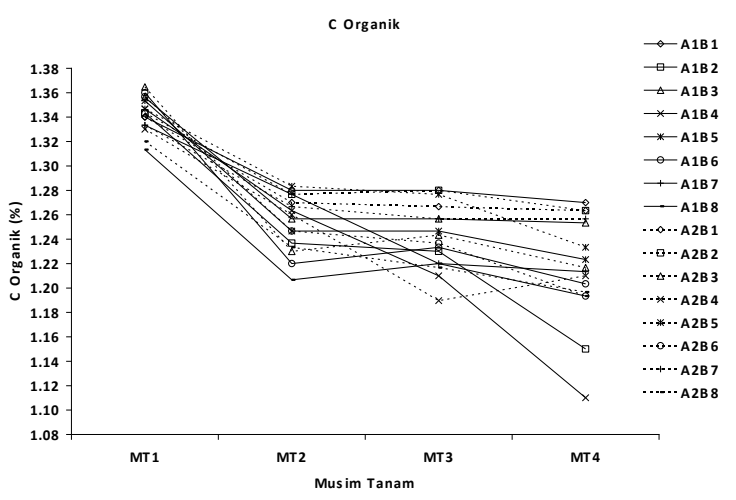

Gambar 2. Grafik C-Organik Tanah selama Empat Musim Tanam

Kandungan C-organik pada kondisi tergenang maupun intermitten terlihat tidak berbeda nyata, demikian pula dengan perlakuan pemupukan menunjukkan nilai C-organik berada pada kriteria rendah. Hal ini disebabkan karena analisis tanah dilakukan setelah panen dimana pupuk yang diberikan ke dalam tanah telah diserap oleh tanaman selama masa 
pertumbuhannya. Penurunan kadar C-organik tanah yang tidak signifikan pada akhir setiap musim tanam menunjukkan bahwa pemberian pupuk sesuai dengan kebutuhan tanaman selama masa pertumbuhan karena pemberian pupuk dilakukan sesuai rekomendasi. Efisiensi pemberian pupuk merupakan cara untuk menghemat input produksi dan juga sebagai salah satu upaya menjaga kelestarian lingkungan karena pemberian pupuk berlebih dapat merusak sifat fisik tanah.

\section{N-total}

Hasil analisis $\mathrm{N}$-total menunjukkan nilai $\mathrm{N}$ yang semakin tinggi pada setiap musim tanam, meskipun masih tergolong rendah. Hal ini disebabkan oleh serapan oleh tanaman padi. Kadar N-total pada MT I berkisar 0,14-0,15\%, kemudian meningkat pada MT II berkisar 0,15 $0,17 \%$, selanjutnya pada MT III berkisar 0,17 $0,18 \%$, dan sedikit mengalami fluktuasi pada MT IV yaitu berkisar $0,14-0,22 \%$. Hal tersebut sesuai dengan pendapat Tan (1993) bahwa perlakuan beberapa rekomendasi pemupukan dengan sistem pengairan intermittent dan tergenang tidak menunjukkan perbedaan yang signifikan karena hara $\mathrm{N}$ merupakan hara yang mobil, dan mudah hilang melalui pencucian, nitrifikasi, denitrifikasi dan folatilisasi.

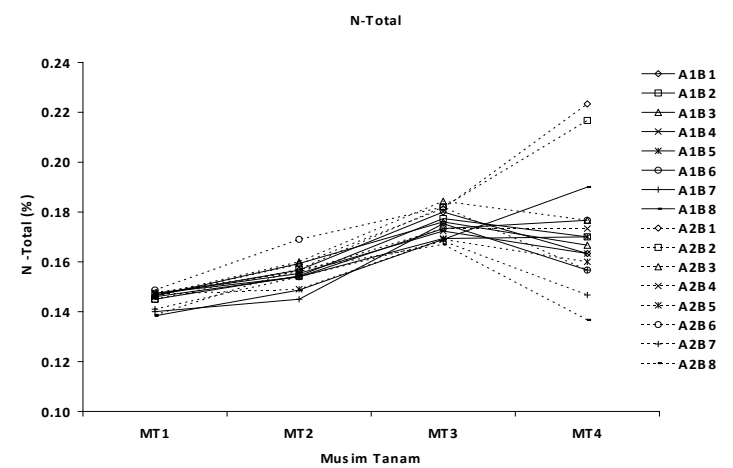

Gambar 3. Grafik N-total Tanah selama Empat Musim Tanam

\section{P-tersedia}

Keragaan $\mathrm{P}$ tersedia pada empat musim tanam tergolong sedang dengan kisaran 9,43 9,79 ppm pada MT I, pada MT II berkisar 8,93 9,45ppm, pada MT III berkisar 8,86 - 9,34ppm, dan pada MT IV berkisar 8,18-8,59ppm. Kadar P-tersedia umumnya tidak menunjukkan perbedaan disebabkan karena pemberian pupuk yang sesuai dengan rekomendasi sehingga sesuai dengan kebutuhan tanaman. P-tersedia pada MT IV terjadi penurunan, hal ini disebabkan $P$ terikat oleh Fe (Kasno, Sulaeman, \& Mulyadi, 1999).

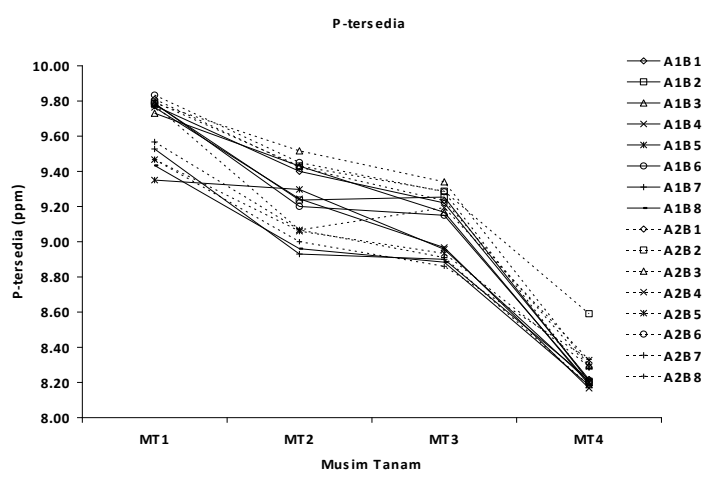

Gambar 4. Grafik P-tersedia selama Empat Musim Tanam

\section{K-dapat Ditukar}

Keragaan K-dapat ditukar pada empat musim tanam tergolong rendah sampai sedang dengan kisaran 0,23 - 0,26 pada MT I, pada MT II berkisar 0,27-0,35, pada MT III berkisar 0,280,34, dan pada MT IV berkisar 0,29 - 0,37. Kadar K-dapat tukar menunjukkan peningkatan. Hal ini menunjukkan bahwa pemberian pupuk $\mathrm{K}$ sudah mencukupi kebutuhan tanaman sehingga menungkinkan untuk mengurangi pemberian pupuk $\mathrm{K}$ ke dalam tanah agar tidak terjadi penumpukan hara $\mathrm{K}$. Keseimbangan hara di dalam tanah sangat penting karena ketidakseimbangan hara maupun kelebihan salah satu unsur hara dapat menyebabkan defisiensi hara tertentu. Krishnasamy et al., (2003) melaporkan bahwa produktivitas lahan pada sistem irigasi berselang lebih tinggi $6,73 \%$ dibanding penggenangan.

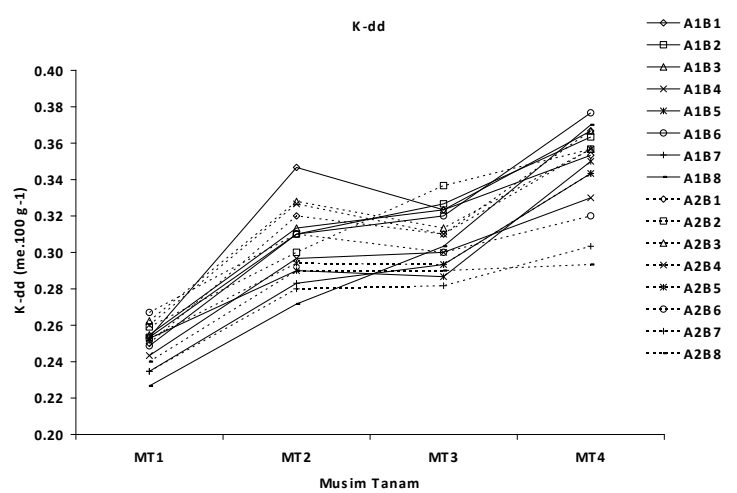

Gambar 5. Grafik K-dd selam Empat Musim Tanam 
Tabel 2. Nilai F Hitung Parameter Kualitas Tanah Selama Empat Musim Tanam

\begin{tabular}{|c|c|c|c|c|c|c|c|c|c|c|c|c|}
\hline \multirow{2}{*}{ Parameter } & \multicolumn{6}{|c|}{ Musim Tanam I } & \multicolumn{6}{|c|}{ Musim Tanam II } \\
\hline & $\mathbf{A}$ & & B & & $\mathbf{A x B}$ & & $\mathbf{A}$ & & B & & $\mathbf{A x B}$ & \\
\hline pH & 134.06 & ** & 30.23 & ** & 13.47 & ** & 159.99 & ** & 26.59 & ** & 26.26 & ** \\
\hline C-organik & 1.00 & tn & 5.18 & ** & 0.40 & tn & 64.00 & tn & 11.15 & ** & 4.75 & ** \\
\hline N-Total & 0.25 & tn & 75.94 & ** & 0.50 & tn & 26.29 & ** & 28.60 & $* *$ & 16.50 & ** \\
\hline P-tersedia & 175.56 & ** & 56.92 & ** & 0.56 & tn & 7.63 & tn & 68.84 & ** & 14.77 & ** \\
\hline K-dd & 1.32 & tn & 10.05 & ** & 1.69 & tn & 4.26 & th & 44.91 & $* *$ & 10.18 & ** \\
\hline \multirow{2}{*}{ Parameter } & \multicolumn{6}{|c|}{ Musim Tanam I } & \multicolumn{6}{|c|}{ Musim Tanam II } \\
\hline & $\mathbf{A}$ & & B & & AxB & & $\mathbf{A}$ & & B & & $\mathbf{A x B}$ & \\
\hline pH & 134.06 & ** & 30.23 & ** & 13.47 & ** & 159.99 & ** & 26.59 & ** & 26.26 & ** \\
\hline C-organik & 1.00 & tn & 5.18 & ** & 0.40 & tn & 64.00 & th & 11.15 & ** & 4.75 & ** \\
\hline N-Total & 0.25 & tn & 75.94 & ** & 0.50 & tn & 26.29 & ** & 28.60 & ** & 16.50 & ** \\
\hline P-tersedia & 175.56 & ** & 56.92 & ** & 0.56 & tn & 7.63 & tn & 68.84 & ** & 14.77 & ** \\
\hline K-dd & 1.32 & tn & 10.05 & ** & 1.69 & tn & 4.26 & tn & 44.91 & $* *$ & 10.18 & ** \\
\hline
\end{tabular}

$* *=$ berbeda nyata pada taraf $1 \% ; *=$ berbeda nyata pada taraf $5 \%$; tn $=$ tidak nyata

$\mathrm{A}=$ sistem pengairan; $\mathrm{B}=$ pemupukan; $\mathrm{AxB}=$ interaksi antara faktor pengairan dan pemupukan

Berdasarkan tabel di atas diperoleh bahwa $\mathrm{pH}$ tanah berbeda nyata pada taraf $1 \%$ terhadap perlakuan pengairan selama empat musim tanam, sedangkan perlakuan pemupukan dan interaksi pemupukan dengan pengairan berbeda nyata pada MT I, MT II dan MT III. Pada MT IV diperoleh bahwa $\mathrm{pH}$ tanah tidak berbeda nyata terhadap pemupukan maupun interaksi pemupukan dengan pengairan. Hal ini menunjukkan bahwa perlakuan pengairan yang mengakibatkan $\mathrm{pH}$ berbeda nyata, sedangkan perlakuan pemupukan dan interaksi pemupukan dengan pengairan selama empat musim tanam penanaman intensif dalam setahun mengakibatkan $\mathrm{pH}$ tidak berbeda nyata pada MT IV.

Kandungan C-organik tanah berbeda nyata terhadap perlakuan pemupukan selama empat musim tanam. Sedangkan kandungan C-organik perlakuan pengairan tidak berbeda nyata pada MT I, MT II dan MT III, kecuali pada MT IV kandungan C-organik berbeda nyata terhadap perlakuan pengairan. Hal ini menunjukkan perbedaan laju dekomposisi bahan organik akibat pemupukan baik pada penggenangan terus-terus menerus dengan intermittent. Untuk kandungan N-total, P-tersedia dan K-dd adalah berbeda nyata dipengaruhi oleh pemupukan sampai musim tanam ke tiga pada musim tanam ke empat pemupukan tidak bereda nyata terhadap P-tersedia dan K-dd. Hal ini menunjukkan bahwa kombinasi pupuk (N, P, dan K) mempengaruhi efisiensi penggunaan hara. Perubahan kombinasi pupuk N, P, dan K menyebabkan efisiensi penggunaan hara $\mathrm{N}, \mathrm{P}$, dan K juga berubah (Syafruddin, Rauf, Arvan, \& Akil, 2006).

\section{KESIMPULAN}

Secara umum penanaman padi secara intensif selama empat musim tanam tidak mengakibatkan perubahan $\mathrm{pH}$ tanah yang tinggi, rata-rata $\mathrm{pH}$ tanah cenderung stabil. Kandungan $\mathrm{N}$-total dan K-dapat ditukar tanah mengalami peningkatan, kemungkinan akibat pemupukan yang dilakukan selama empat musim tanam. Sedangkan C-organik dan P-tersedia tanah mengalami penurunan, pada perlakuan intermitten penurunan kandungan $\mathrm{C}$-organik lebih tinggi dari pada penggenangan terus menerus. 


\section{DAFTAR PUSTAKA}

Agus, F., \& Mulyani, A. (2006). Judicious use of land resources for sustaining Indonesian rice self sufficiency. Rice Industry, Culture and Environment (Book 1). Sukamandi: Indonesian Center for Rice Research.

Departemen Pertanian. (2008). Peningkatan produksi padi menuju 2020: Memperkuat kemandirian pangan dan pluang ekspor. Jakarta: Departemen Pertanian.

Hardjowigeno. (1987). Ilmu Tanah (Ed. Revisi). Jakarta: PT. Mediyatama Sarana Perkasa.

Hartatik, W., Widowati, L., Retno, \& Sulaeman. (2007). Pengaruh Potensial Redoks Terhadap Ketersediaan Hara pada Tanaman Padi Sawah. Prosiding Pertemuan Pembahasan Dan Komunikasi Hasil Penelitian Tanah Dan Agroklimat, 19-33. Bogor.

Ismunadji, M., Partohardjono, S., Syam, M. M., \& Widjono, A. (1988). Padi (Buku 1). Bogor: Puslitbang Tanaman Pangan.

Kasno, A., Sulaeman, \& Mulyadi. (1999). Pengaruh Pemupukan dan Pengairan Terhadap Eh, pH, Ketersediaan P dan Fe Serta Hasil Padi pada Tanah Sawah Bukaan Baru. Jurnal Tanah Dan Iklim, 17(1), 72-81.

Krishnasamy, S., Amerasinghe, F. P., Sakthivadivel, R., Ravi, G., Tewari, S. C., \& Hoek, W. Van Der. (2003). Strategies for conserving water and effecting mosquito vector control in rice ecosystems: A case study from Tamil Nadu, India. In IWMI Vol 56.

Mitchell, J., Gaskell, M., Smith, R., Fouche, C., \& Koike, S. T. (2000). Soil Management and Soil Quality for Organic Crops. https://doi.org/10.3733/ucanr.7248

Ramija, K., Manurung, E. D., Batubara, S. F., \& Susanto, A. N. (2016). Evaluasi

Kualitas Air Irigasi pada Budidaya Padi IP 400 di Kabupaten Simalungun. Prosiding Seminar Nasional Membangun Pertanian Modern Dan Inovatif Berkelanjutan Dalam Rangka Mendukung MEA. Kementrian Pertanian RI.

Syafruddin, Rauf, M., Arvan, R. Y., \& Akil, M. (2006). Kebutuhan Pupuk N, P, dan K Tanaman Jagung pada Tanah Incepticol Haplustepts. Jurnal Penelitian Pertanian Tanaman Pangan, 25(1), 1-8.
(Edisi I; H. G. Didiek, Ed.). Yogyakarta: Gadjah Mada University Press.

Yetro, K. (2014). Analisis Pengelolaan Lahan Pertanian Untuk Peningkatan Kesejahteraan Petani Padi (Studi Kasus di Desa Pandenganploso Kabupaten Lamongan). Universitas Wijaya Putra.

Zaini, Z. (2012). Pupuk majemuk dan pemupukan hara spesifik lokasi pada padi sawah. Iptek Tanaman Pangan, 7(1), 1-7.

Tan, K. H. (1993). Dasar-Dasar Kimia Tanah 